\title{
Breakthroughs in lung cancer management
}

\section{Avances en el manejo del cáncer de pulmón}

https://doi.org/10.23938/ASSN.0886

L.M. Montuenga ${ }^{1-3}$, J.J. Zulueta ${ }^{3,4}$

In the present issue of Anales del Sistema Sanitario de Navarra, Rico et al summarize the progress in key areas of the radiotherapeutic strategies to fight against advanced lung cancer ${ }^{1}$. Progress in radiotherapy strategies for lung cancer management has been remarkable in the last decade. We will devote some comments in the present editorial to these achievements. Nevertheless, radiotherapy (RT) has been only one of the many areas that have benefited from successful basic, translational and clinical research in lung cancer during the last decade. In the following paragraphs, we will very briefly mention some of these breakthroughs and seminal achievements that have improved the survival prospects of lung cancer patients in the decade from 2010 to 2020.

The American Cancer Society 2020 report on cancer statistics ${ }^{2}$ has informed that, according to their data, the overall cancer mortality in the last two decades has followed a pace of steady reduction. Specifically, an average $1.5 \%$ yearly reduction of overall cancer death rates between 2008 and 2017 was reported in the US. The key effect of the large decrease in lung cancer figures in the general cancer mortality is discussed. Even considering that in the US lung cancer is the deadliest tumor in both males and females, accounting for around $22 \%$ of the total cancer deaths in both sexes, among the major drivers of the decline in overall cancer mortality is the reduction of lung cancer deaths. The authors of this widely acknowledged statistical review make clear that, although lung cancer incidence and mortality is a major public health problem, the decline of mortality rates in lung cancer in the last analyzed years is remarkable. Their statistics for 2013 to 2017 clearly show that declines in lung cancer mortality have accelerated, from ap-

1. Solid Tumors Program. Center of Applied Medical Research (CIMA). University of Navarra. Pamplona, Spain.

2. Department of Pathology, Anatomy and Physiology. Schools of Medicine and Sciences. University of Navarra. Pamplona, Spain.

3. Instituto de Investigación Sanitaria de Navarra (IdisNa). Pamplona, Spain.

4. Pulmonary Service. Clínica Universidad de Navarra. Pamplona, Spain.

\author{
Corresponding author: \\ Luis M. Montuenga \\ Solid Tumors Program \\ Center of Applied Medical Research (CIMA) \\ University of Navarra \\ Avda. Pío XII, 55 \\ 31008 Pamplona \\ Navarra (Spain) \\ E-mail: Imontuenga@unav.es
}


proximately $3 \%$ annually between $2008-2013$ to $5 \%$ between $2013-2017$ in men; and from $2 \%$ to almost $4 \%$ in women. When looking at these data, it is evident that the policies and public awareness efforts to reduce smoking at the population level are indeed extremely beneficial, and can be considered the main cause of the subsequent decline in mortality. However, the decline in lung cancer mortality is not only a matter of reduced incidence, but also of improved survival. Those of us who have been working in lung cancer research in the last two decades have witnessed the impressive and uncontroversial increase of a large list of innovative treatments approved for lung cancer patients, which have influenced very positively in reducing the mortality burden due to lung tumors. In the next paragraphs, we will very briefly review some examples of these breakthrough achievements in the last decade, starting in 2010.

During the last ten years, a large number of positive practice-changing clinical achievements, which have profoundly improved the disease outcome, have benefited every area involved in the management of lung cancer patients (surgery, radiotherapy, pathology, oncology, and respiratory medicine). The way lung cancer patients are managed nowadays as compared to ten years ago has also changed remarkably. Examples of this stunning progress have been excellently described by Dr Kara Nyberg in the April 2020 IASLC Lung Cancer News issue ${ }^{3}$. Some of them are also mentioned in the present editorial.

\section{Immunotherapy}

The news of the award of the 2018 Nobel Prize in Physiology or Medicine to Tasuku Honjo and James Allison for their discoveries in cancer immunology ${ }^{4}$ has confirmed the relevance of the therapeutic strategies based on the modulation of the antineoplastic immune response. In the case of lung cancer, the introduction in 2015 of immune checkpoint inhibitors for the treatment of non-small cell lung cancer (NSCLC) is indeed one of the most important breakthroughs of the present decade ${ }^{3}$. Several drugs, such as nivolumab, pembrolizumab or atezolizumab, were approved in 2015 for a large number of indications in lung cancer management, initially for late stage metastatic tumors progressing on previous chemotherapeutic conventional drugs. One year later, immunotherapy was already approved for the first line setting in metastatic PDL-1 expressing NSCLC, with no EGFR or ALK genomic aberrations. Since then, checkpoint inhibitors, either alone or combined with chemotherapy, are now a standard of care for advanced NSCLC patients for which a driver mutation is not found. For example, in 2019 pembrolizumab was approved as single therapy for first-line treatment of patients with stage III NSCLC who are not candidates for surgical resection or definitive chemoradiation or metastatic NSCLC ${ }^{5,6}$. Other very encouraging recent news is the Food and Drug Administration (FDA) approval of two immunotherapy drugs (embrolizumab and atezolizumab) for extensive-stage small-cell lung cancer (SCLC) ${ }^{7,8}$. The search for biomarkers (expression of PDL-1 or other immune checkpoint proteins, tumor mutation burden, genomic tumor aberrations landscape, neoantigen production levels, antigen 
presentation capability, etc.) to select those patients who will likely respond to the immune-based therapies, or that may develop resistance, is getting a lot of attention and is becoming an extremely active field $^{9}$.

\section{Targeted therapies}

In 2010 only two targeted therapies, directed against EGFR mutations, were available in the daily practice: gefitinib and erlotinib. In the last ten years, around 20 new agents have been developed and approved: therapies targeted to lung cancer driver mutations, antiangiogenic drugs and immune checkpoint inhibitors. Just as some significant examples, a selection of major practice changing targeted therapies achievements of the decade will be mentioned here. There are currently several first line EGFR-targeted therapies, the most recent of which are to be used when resistance mutations to previous EGFR tyrosine kinase inhibitors (TKI) targeted treatments take the driving role in the tumor. For example, osimertinib was granted accelerated approval in 2015 for cases with advanced NSCLC that developed the resistance mutation T790M on or after treatment with EGFR TKI of the previous generation. Posteriorly, the FLAURA Phase III trial, compared osimertinib with the precious generation EGFR TKIs gefitinib or erlotinib in patients with previously untreated, EGFR mutation-positive, advanced NSCLC. This trial found significant improvements in progression free survival and overall survival for the patients treated with osimertinib. Osimertinib showed efficacy superior to that of standard EGFR-TKIs in the first-line treatment of EGFR mutation-positive advanced NSCLC, with a similar safety profile and lower rates of serious adverse events (ClinicalTrials.gov number NCT02296125) ${ }^{4}$. In 2018, it has also been approved for metastatic NSCLC with conventional EGFR exon 19 deletions or exon $21 \mathrm{~L} 858 \mathrm{R}$ mutations ${ }^{10,11}$. Thus, osimertinib is becoming the standard of care in the presence of EGFR resistance mutations in many areas of the world. Other mayor achievement examples in the area of targeted therapies are the different drugs approved for patients with ALK rearrangements. There have also been several generations of drugs, from crizotinib, approved in 2011 for ALK-rearranged advanced NSCLC, to next generation drugs alectinib, ceritinib, brigatinib or, lately, loratinib. A phase II study published in 2018 showed that substantial overall and intracranial activity of loratinib was achieved both in treatment-naive patients with ALK-positive NSCLC, and in those who had progressed on crizotinib, second-generation ALK tyrosine kinase inhibitors, or after up to three previous ALK tyrosine kinase inhibitors. These results prompted FDA approval for loratinib in these patients ${ }^{12,13}$. Other mutational NSCLC driver events as ROS1 rearrangements or NTRK mutations have been also related to specific drugs, which have been approved in recent years for personalized treatment of mutated cases $^{13-18}$. The FDA keeps approving new inhibitors for protein kinases for different conditions and targets. Up to 2020, it has approved 52 small molecule protein kinase inhibitors, nearly all of which are given orally. Among these drugs, 46 are aimed for neoplastic diseases (41 against solid tumors) ${ }^{18}$. 


\section{Radiotherapy}

During the last decade, lung cancer patients have benefited from refinement and new technical approaches based on radiation therapy. Proton therapy, for example, has improved significantly its efficacy for lung cancer treatment ${ }^{19}$. In the present issue of Anales, Rico et al summarize the progress in key areas of the radiotherapeutic strategies to fight against advanced lung cancer. The authors conclude that hypofractionated $\mathrm{RT}$ and stereotactic body radiation therapy (SBRT) will be very relevant in the management of NSCLC patients at stage III in the future ${ }^{1}$. They suggest that, although clinical trials are needed to determine the best fractionation and combination schemes, hypofractionation, together with chemotherapy (CT) or immunotherapy may be an appropriate treatment for patients that are not candidates for concurrent chemo-radio therapies. On the other hand, Rico et al conclude that SBRT, in this locally advanced stage, may be indicated after concurrent CRT. Currently ongoing clinical trials may indeed help to clarify the potential benefits of integration of SBRT with immunotherapy or other targeted treatments. In recent years, stereotactic ablative radiotherapy (SABR) has been proposed and tested for patients at earlier stages that may be unsuitable for surgical treatment for several reasons. Several professional societies have released guidelines for the use of SABR in early lung cancer patients in this context ${ }^{20,21}$. Currently ongoing clinical trials may indeed help further clarify the potential benefits of integration of radiotherapy with immunotherapy. The phase III PACIFIC trial has been a key breakthrough in the study of the combination of RT and immunotherapy in NSCLC ${ }^{22-24}$. In this trial, stage III NSCLC patients were treated with concurrent chemoradiation and adjuvant durvalumab was randomized in two groups. In the durvalumab arm median survival was not reached and 2-year OS was $66.3 \%$, while the control cohort showed a median survival of 28.7 months and 2 -year OS of $55.6 \%$. These are extremely encouraging results for the management of stage III NSCLC. Other trials are ongoing to better define the value of this combined strategy $^{25}$. For example, the PACIFIC-4 trial (NCT03833154) is currently recruiting patients. It is a phase III, randomized, placebo-controlled, double-blind, multi-center study assessing the efficacy and safety of durvalumab versus placebo following standard of care SBRT in patients with unresected clinical stage I/II lymph node-negative (T1 to T3N0M0) NSCLC.

The effects of radiotherapy in the immune system and its potential synergies with immunotherapy strategies are the object of very intense current research ${ }^{26}$. In their study, Rico et al mention some open questions. Indeed, some other very intriguing and relevant biological aspects are currently being studied and can be the basis of targeted combinations of immunomodulating drugs and radiotherapeutical interventions. It is now very clear that radiotherapy of cancer has a plethora of biological effects on both malignant and stromal cells beyond simple killing of tumor cells ${ }^{27}$. Many research groups have shown that radiation-induced inflammation and cell death lead to a large number of effects in the local and systemic immune response, which could be the basis of new combined immunotherapies. Other very relevant and intriguing question, clearly demonstrated in different settings, is that 
both radiation and immunotherapy do not only act in the irradiated tumor local area, but also may induce responses in distant non-irradiated metastatic lesions (abscopal effects) ${ }^{28,29}$.

\section{Surgery}

The major efforts in lung cancer surgery in the last decade have been devoted to decrease the invasiveness of the technical approaches to remove the malignant lesion preserving oncologic treatment success. Video-assisted thoracic surgery (VATS), which was first developed in the $90 \mathrm{~s}$, has been increasingly incorporated in the armamentarium of thoracic surgeons, and many centers prefer this less invasive surgical strategy rather than open thoracotomy because of its reduced morbility ${ }^{30-33}$. The initial results, communicated in meetings but still not published, of the VIOLET trial seem very encouraging. The VIOLET trial is a randomized controlled trial comparing the effectiveness, cost-effectiveness and acceptability of VATS lobectomy versus open lobectomy for treatment of lung cancer ${ }^{34}$. Other very exciting achievements and developments in surgical treatment of lung cancer are the development of robotic-assisted thoracic surgery $\mathrm{y}^{35-37}$ and uniportal VATS ${ }^{38}$. Although randomized trials are still required, these novel technologies seem to improve pain control and shorten the duration of hospital stay. Additionally, innovative interventional bronchoscopy has also helped the management, safety and effectiveness of bronchoscopic technologies. Finally, progress has been made in the present decade in the understanding of the relevance of mediastinal lymphadenectomy for the precise staging of the patients ${ }^{39}$.

\section{Prevention and early detection}

Several reports show that the prevalence of smoking is decreasing, at least in developed countries, mainly due to primary prevention achieved by awareness and regulatory policies. Nevertheless, exposure to tobacco smoke as well as other carcinogenic environmental toxicants such as asbestos, radon, heavy pollution, etc. continues to be a remarkable burden for health all over the world ${ }^{40,41}$. Some estimations calculate that about one billion people are still smoking cigarettes worldwide. Moreover, a new potential epidemiological risk factor has appeared in the last decade: the increase in persons using e-cigarettes and other vaping devices ${ }^{42}$. A major breakthrough in the present decade has been the demonstration, by several large international randomized trials (NLST in 2011; NELSON in 2018), of the reduction in lung cancer mortality at the population level by low-dose CT (LDCT) lung cancer screening in high risk individuals ${ }^{43-45}$. In the NLST trial, which included 53,454 ever smokers with at least a 30 pack year history and 55 to 74 years old, the group assigned to LDCT showed a reduction in lung cancer mortality of at least $20 \%$ as well as a $6.7 \%$ reduction of overall mortality ${ }^{44}$. Similar results have been announced in Europe in the NELSON trial ${ }^{45}$. Based on the data published by NLST, the US Preventive Task Force officially recommended in 2013 LDCT on a yearly basis for the individuals with identical age and smoking exposure as the NLST inclusion criteria. How- 
ever, evidence shows that up to $50 \%$ of patients with lung cancer do not meet these criteria ${ }^{46}$. Since then, a large number of studies are trying to refine the risk models, inclusion criteria, screening protocols, early-stage NSCLC diagnosed patients management, etc. In fact, the U.S. Preventive Services Task Force (USPSTF) has just published for public comment an updated draft of its lung cancer inclusion criteria. These revised criteria reduce the age of entry to 50 years old, and the tobacco history to 20 pack-years. There are also a large number of studies trying to develop biomarkers-based methods to improve the accuracy of risk models, increase LDCT specificity, improve the characterization of the indeterminate nodules found by the imaging technologies or improve the prognosis information of the diagnosed tumors ${ }^{47}$. These biomarkers consist mainly in the analysis of circulating blood molecules or breath analysis.

It is clear that from the Public Heath perspective we are currently in a very exciting moment. It is very likely that in the decade that we have just started in 2020, through smoking reduction and high-risk individual lung cancer screening programs we will considerably reduce the incidence and mortality of lung cancer: one of the worst epidemics in the present and past centuries.

\section{Acknowledgements}

LMM research work is supported by Foundation for Applied Medical Research (FIMA), CIBERONC, Fundación Científica de la Asociación Española Contra el Cáncer, Fundación Ramón Areces, and Fondo de Investigación Sanitaria-Fondo Europeo de Desarrollo Regional "Una manera de hacer Europa" (PI19/00098).

\section{REFERENCES}

1. Rico M, Flamarique Andueza S, Martín Martínez A, Rodríguez Mendizábal MA, Rosas Gutiérrez L, MARTínez López E. How to integrate stereotactic body radiation therapy and hypofractionation in the management of stage III lung cancer in the age of immunotherapy. An Sist Sanit Navar 2020; 43: 225-234. https://doi. org/10.23938/ASSN.0855

2. Siegel RL, Miller KD, Jemal A. Cancer statistics, 2020. CA Cancer J Clin 2020; 70: 7-30. https://doi.org/10.3322/caac. 21590

3. NYBERG K. Stunning progress achieved in lung cancer treatment over the last decade. IASLC Lung Cancer News 2020. https://www.lungcancernews. org/2020/04/16/stunning-progress-achieved-in-lung-cancer-treatment-overthe-last-decade/

4. Huang P-W, Chang JW-C. Immune checkpoint inhibitors win the 2018 Nobel Prize. Biomed J 2019; 42: 299-306. https://doi.org/10.1016/j.bj.2019.09.002

5. Brassart-Pasco S, Dalstein V, Brassart B, Dewolf M, Clavel C, Oudart J-B. Immunotherapy in non-small-cell lung cancer: from targeted molecules to resistance patterns. Pharmacogenomics 2020; 21: 705-720. https://doi.org/10.2217/ pgs-2020-0021

6. Uprety D, Mandrekar SJ, Wigle D, Roden AC, Adjei AA. Neoadjuvant immunotherapy for non-small cell lung cancer: current concepts and future approaches. J Thorac Oncol 2020; 15: 1281-1297. https://doi.org/10.1016/j.jtho.2020.05.020 
7. Gill J, Cetnar JP, Prasad V. A timeline of immune checkpoint inhibitor approvals in small cell lung cancer. Trends Cancer 2020; 29. https://doi. org/10.1016/j.trecan.2020.05.014

8. Ragavan M, DAS M. Systemic therapy of extensive stage small cell lung cancer in the era of immunotherapy. Curr Treat Options Oncol 2020; 21: 64. https:// doi.org/10.1007/s11864-020-00762-8

9. Rossi G, Russo A, Tagliamento M, Tuzi A, Nigro O, Vallome G et al. Precision medicine for NSCLC in the era of immunotherapy: new biomarkers to select the most suitable treatment or the most suitable patient. Cancers 2020; 12. https://doi.org/10.3390/cancers 12051125

10. Soria J-C, Ohe Y, Vansteenkiste J, Reungwetwattana T, Chewaskulyong B, Lee KH et al. Osimertinib in untreated EGFR-mutated advanced non-small-cell lung cancer. N Engl J Med 2018; 378: 113-125. https://doi.org/10.1056/NEJMoa1713137

11. Ramalingam SS, Vansteenkiste J, Planchard D, Cho BC, Gray JE, Ohe Y et al. Overall survival with osimertinib in untreated, EGFR-mutated advanced NSCLC. N Engl J Med 2020; 382: 41-50. https://doi.org/10.1056/nejmoa1913662

12. Solomon BJ, Besse B, Bauer TM, Felip E, Soo RA, Camidge DR et al. Lorlatinib in patients with ALK-positive non-small-cell lung cancer: results from a global phase 2 study. Lancet Oncol 2018; 19: 1654-1667. https://doi.org/10.1016/ s1470-2045(18)30649-1

13. Shaw AT, Solomon BJ, Chiari R, Riely GJ, Besse B, Soo RA et al. Lorlatinib in advanced ROS1-positive non-small-cell lung cancer: a multicentre, open-label, single-arm, phase 1-2 trial. Lancet Oncol 2019; 20: 1691-1701. https://doi. org/10.1016/s1470-2045(19)30655-2

14. Drilon A, Siena S, Ou S-HI, Patel M, Ahn MJ, Lee J et al. Safety and antitumor activity of the multitargeted pan-TRK, ROS1, and ALK inhibitor entrectinib: combined results from two phase I trials (ALKA-372-001 and STARTRK-1). Cancer Discov 2017; 7: 400-409. https://doi.org/10.3410/f.727294853.793541382

15. Drilon A, Siena S, Dziadziuszko R, Barlesi F, Krebs MG, Shaw AT et al. Entrectinib in ROS1 fusion-positive non-small-cell lung cancer: integrated analysis of three phase 1-2 trials. Lancet Oncol 2020; 21: 261-270. https://doi.org/10.1016/ S1470-2045(19)30690-4.

16. DuRuISSEAUX M. Lorlatinib: a new treatment option for ROS1-positive lung cancer. Lancet Oncol 2019; 20: 1622-1623. https://doi.org/10.1016/s14702045(19)30716-8

17. LASSEN U. Entrectinib for ROS1 fusion-positive NSCLC and NTRK fusion-positive solid tumours. Lancet Oncol 2020; 21: 193-194. https://doi.org/10.1016/ s1470-2045(19)30789-2

18. Rоккоккі RJ. Properties of FDA-approved small molecule protein kinase inhibitors: A 2020 update. Pharmacol Res 2020; 152: 104609. https://doi. org/10.1016/j.phrs.2019.104609

19. HAN Y. Current status of proton therapy techniques for lung cancer. Radiat Oncol J 2019; 37: 232-248. https://doi.org/10.3857/roj.2019.00633

20. Videtic GMM, Donington J, Giuliani M, Heinzerling J, Karas TZ, Kelsey CR et al. Stereotactic body radiation therapy for early-stage non-small cell lung cancer: Executive Summary of an ASTRO Evidence-Based Guideline. Pract Radiat Oncol 2017; 7: 295-301. https://doi.org/10.1016/j.prro.2017.04.014

21. Guckenberger M, Andratschke N, Dieckmann K, Hoogeman MS, Hoyer M, Hurkmans $\mathrm{C}$ et al. ESTRO ACROP consensus guideline on implementation and practice of stereotactic body radiotherapy for peripherally located early stage non-small cell lung cancer. Radiother Oncol 2017; 124 : 11-17. https://doi. org/10.1016/j.radonc.2017.05.012

22. Antonia SJ, Villeggas A, Daniel D, Vicente D, Murakami S, Hui R et al. Overall survival with durvalumab after chemoradiotherapy in stage III NSCLC. N Engl J Med 2018; 379: 2342-2350. https://doi.org/10.1056/NEJMoa1809697 
23. Paz-Ares L, Spira A, Raben D, Planchard D, Cho BC, Özgüro lu M et al. Outcomes with durvalumab by tumour PD-L1 expression in unresectable, stage III non-small-cell lung cancer in the PACIFIC trial. Ann Oncol 2020; 31: 798-806. https://doi.org/10.1016/j.annonc.2020.03.287

24. Gray JE, Villegas A, Daniel D, Vicente D, Murakami S, Hui R et al. Three-year overall survival with durvalumab after chemoradiotherapy in stage iii NSCLC - Update from PACIFIC. J Thorac Oncol 2020; 15: 288-293. https://doi. org/10.1016/j.jtho.2019.10.002

25. Yamada T, Uchino J, Chinara Y, Shimamoto T, Imasaku M, TamiYa $\mathrm{N}$ et al. Rationale and design of a phase II trial of durvalumab treatment in patients with NSCLC ineligible for stage III chemoradiotherapy following radiation monotherapy (SPIRAL-RT study). Ther Adv Med Oncol 2020; 12. https://doi. org/10.1177/1758835920927841

26. Walle T, Martinez Monge R, Cerwenka A, Ajona D, Melero I, Lecanda F. Radiation effects on antitumor immune responses: current perspectives and challenges. Ther Adv Med Oncol 2018; 10.. https://doi.org/10.1177/1758834017742575

27. Rodriguez-Ruiz ME, Vitale I, Harrington KJ, Melero I, Galluzzi L. Immunological impact of cell death signaling driven by radiation on the tumor microenvironment. Nat Immunol 2020; 21: 120-134. https://doi.org/10.1038/s41590-0190561-4

28. Rodríguez-Ruiz ME, Vanpouille-Box C, Melero I, Formenti SC, Demaria S. Immunological mechanisms responsible for radiation-induced abscopal effect. Trends Immunol 2018; 39: 644-655. https://doi.org/10.1016/j.it.2018.06.001

29. Rodriguez-Ruiz ME, Rodriguez I, Leaman O, López-Campos F, Montero A, Conde AJ et al. Immune mechanisms mediating abscopal effects in radioimmunotherapy. Pharmacol Ther 2019; 196: 195-203. https://doi.org/10.1016/j.pharmthera.2018.12.002

30. Berfield KS, FarJah F, Mulligan MS. Video-Assisted thoracoscopic lobectomy for lung cancer. Ann Thorac Surg 2019; 107: 603-609. https://doi.org/10.1016/j. athoracsur.2018.07.088

31. Chat T, LiN Y, Kang M, Lin J. Thoracotomy versus video-assisted thoracoscopic resection of lung cancer: A protocol for a systematic review and metaanalysis. Medicine (Baltimore) 2019; 98: e14646. https://doi.org/10.1097/ md.0000000000014646

32. Chai T, LiN Y, Shen Z, Chen S, Zhang Z, Lin W et al. Comparison between videoassisted thoracoscopic lung cancer resection and robot-assisted lung cancer resection: Protocol for a systematic review and meta-analysis. Medicine (Baltimore) 2019; 98: e14790. https://doi.org/10.1097/md.0000000000014790

33. Zeng W, Zhang W, Zhang J, You G, Mao Y, Xu J et al. Systematic review and metaanalysis of video-assisted thoracoscopic surgery segmentectomy versus lobectomy for stage I non-small cell lung cancer. World J Surg Oncol 2020; 18: 44. https://doi.org/10.1186/s12957-020-01814-x

34. Lim E, Batchelor T, Shackcloth M, Dunning J, McGonigle N, Brush T et al. Study protocol for VIdeo assisted thoracoscopic lobectomy versus conventional Open LobEcTomy for lung cancer, a UK multicentre randomised controlled trial with an internal pilot (the VIOLET study). BMJ Open 2019; 9: e029507. https://doi.org/10.1136/bmjopen-2019-029507

35. Gharagozloo F, Meyer M, Tempesta B. Robotic lobectomy: experience with 638 consecutive cases. Surg Technol Int 2020 May;36:251-256.

36. O'Sullivan KE, Kreaden US, Hebert AE, Eaton D, Redmond KC. A systematic review and meta-analysis of robotic versus open and video-assisted thoracoscopic surgery approaches for lobectomy. Interact Cardiovasc Thorac Surg 2019; 28: 526-534. https://doi.org/10.1093/icvts/ivy315

37. Perroni G, Veronesi G. Robotic segmentectomy: indication and technique. J Thorac Dis 2020; 12: 3404-3410. https://doi.org/10.21037/jtd.2020.02.53 
38. Meacci E, Nachira D, Zanfrini E, Triumbari EKA, Iaffaldano AG, Congedo MT et al. Uniportal VATS approach to sub-lobar anatomic resections: literature review and personal experience. J Thorac Dis 2020; 12: 3376-3389. https://doi. org/10.21037/jtd.2020.01.12

39. Call S, Obiols C, Rami-Porta R. Present indications of surgical exploration of the mediastinum. J Thorac Dis 2018; 10 (Suppl 22): S2601-S2610. https://doi. org/10.21037/jtd.2018.03.183

40. Schuller HM. The impact of smoking and the influence of other factors on lung cancer. Expert Rev Respir Med 2019; 13: 761-769. https://doi.org/10.108 0/17476348.2019.1645010

41. Parascandola M, Xiao L. Tobacco and the lung cancer epidemic in China. Transl lung cancer Res 2019; 8 (Suppl 1): S21-S30. https://doi.org/10.21037/ tlcr.2019.03.12

42. Stone E, Marshall H. Tobacco and electronic nicotine delivery systems regulation. Transl lung cancer Res 2019; 8 (Suppl 1): S67-S76. https://doi. org/10.21037/tlcr.2019.03.13

43. Aberle DR, DeMello S, Berg CD, Black WC, Brewer B, Church TR et al. Results of the two incidence screenings in the National Lung Screening Trial. N Engl J Med 2013; 369: 920-931. https://doi.org/10.1056/nejmoa1208962

44. Aberle DR, Adams AM, Berg CD, Black WC, Clapp JD, Fagerstrom RM et al. Reduced lung-cancer mortality with low-dose computed tomographic screening. N Engl J Med 2011; 365: 395-409. https://doi.org/10.1056/nejmoa1102873

45. De Koning HJ, van der Aalst CM, de Jong PA, Scholten ET, Nackaerts K, HeuvelMANS MA et al. Reduced Lung-cancer mortality with volume CT screening in a randomized trial. N Engl J Med 2020; 382: 503-513. https://doi.org/10.1056/ nejmoa1911793

46. Sanchez-Salcedo P, Wilson DO, De-Torres JP, Weissfeld JL, Berto J, Campo A et al. Improving selection criteria for lung cancer screening: The potential role of emphysema. Am J Respir Crit Care Med 2015; 191. https://doi.org/10.1164/ rccm.201410-1848oc

47. Seijo LM, Peled N, Ajona D, Boeri M, Field JK, Sozzi G et al. Biomarkers in lung cancer screening: achievements, promises, and challenges. J Thorac Oncol 2019; 14: 343-357. https://doi.org/10.1016/j.jtho.2018.11.023 
